\title{
VECTOR CONTROL WITH OPTIMAL TORQUE OF A SALIENT-POLE DOUBLE STAR SYNCHRONOUS MACHINE SUPPLIED BY THREE-LEVEL INVERTERS
}

\author{
Lazhari Nezli - Mohand Oulhadj Mahmoudi *
}

\begin{abstract}
This work relates to the study of the vector control of the salient-pole double star synchronous machine drive (DSSM) fed by three-level inverters which are controlled by PWM hysteresis strategy. Indeed, it is a question of carrying out a decoupling between rotor flux and electromagnetic torque, by introducing a vector control with an optimal torque working and by imposing constant flux regime. Furthermore, to ensure a decoupled dynamic behavior of the machine as in the case of a DC machine, a regulation of the rotor current has been introduced through a chopper operating at $5 \mathrm{kHz}$ chopping frequency, feeding the excitation circuit. The obtained results are very satisfactory and reveal the effectiveness of the proposed approach.
\end{abstract}

Keywords: salient-pole double star synchronous machine, tree-level inverter, decoupled control, optimal torque working, speed regulation

\section{NOMENCLATURE}

$v_{a 1}, v_{b 1}, v_{c 1}$ voltages of stator three phase first winding $v_{a 2}, v_{b 2}, v_{c 2}$ voltages of stator three phase second winding $i_{a 1}, i_{b 1}, i_{c 1}$ stator currents $a, b, c$ phases of first winding $i_{a 2}, i_{b 2}, i_{c 2}$ stator currents $a, b, c$ phases of second winding $v_{d 1}, v_{q 1} \quad$ stator voltages $d q$ components of first winding $v_{d 2}, v_{q 2} \quad$ stator voltages $d q$ components of second winding $i_{d 1}, i_{q 1} \quad$ stator currents $d q$ components of first winding

$i_{d 2}, i_{q 2} \quad$ stator currents $d q$ components of second winding $i_{f} \quad$ DC current of rotor excitation

$\phi_{d 1}, \phi_{q 1} \quad$ stator flux $d q$ axis components of first winding

$\phi_{d 2}, \phi_{q 2} \quad$ stator flux $d q$ axis components of second winding

$R_{s}$ stator resistance

$L_{d}, L_{q} \quad d-q$ inductances

$M_{d}, M_{q} \quad d-q$ magnetizing inductance

$T_{e m}, T_{e m}^{*} \quad$ electromagnetic torque, reference torque

$T_{r} \quad$ load torque

$J \quad$ total inertia

$f_{r} \quad$ coefficient of friction

$K_{p}, K_{d} \quad$ PI parameters of rotor excitation current $i_{f}$

$p \quad$ number of pole pairs

$\omega \quad$ synchronous pulsation

$\Omega \quad$ rotating speed

DSSM double star synchronous machine

$X^{*} \quad$ reference value of $x$

\section{INTRODUCTION}

The electrical AC machines drive play a very important role in industrial applications. The performances requested from these machines are constantly increasing from the point of view of the dynamics speed and of the waveform quality of the delivered torque.

The progress achieved in the domain of the power electronics permitted to construct some static converters at variable frequency which has led to the effective speed drive of the AC machines. For high powers, the use of the synchronous machines associated static inverters especially finds its application in the electric traction and the motorisation at variable speed of the embarked systems $[1,2]$. Among these machines one finds the self-controlled synchronous machines supplied by thyristor components. The great inconvenience met with this type of supply is the high waveform of the electromagnetic torque. To overcome this problem, one uses a three-phase double star synchronous machines whose windings are shifted of 30 degrees one compared to the other, supplied with two inverters $[1-5]$.

The development of the high power components allowed the passage of the voltage supply of these machines with two voltage source inverters (VSI) and their use makes it possible to segment the power which improves commutation of these power components. Moreover, in low and average power, the feeding of this machines is generally assured by two-level inverters, however, for the high power, these machines supply often requires multilevel inverters [6].

Otherwise, the difficulty to control this type of machine resides in the fact that the mathematical model of the system is nonlinear, multi-variable and highly coupled due to the existence of a strong coupling between rotor flux and electromagnetic torque. Several control strategies have been proposed in the literature [5], [7-11]. For the smooth-pole synchronous machines, the decoupling at optimal torque operating is carried out for vector control with imposing direct components of stator current null [10].

This paper forms part of this context and the aim is to propose a new control strategy for achieving a decoupling between rotor flux and electromagnetic torque operating at optimal torque behavior of a salient-pole double star

* Process Control Laboratory, Ecole Nationale Polytechnique, 10 av. Pasteur, Hassen Badi, 16200 El Harrach, Algiers, Algeria, mo.mahmoudi@enp.edu.dz, l_nezli@yahoo.fr 


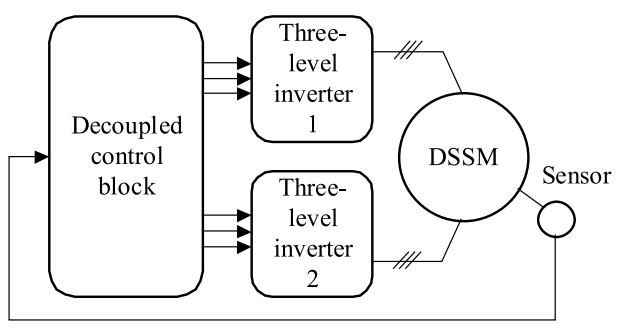

Fig. 1. Synoptic scheme of a vector control DSSM drive

synchronous machine (DSSM) supplied with two threelevel inverters controlled via hysteresis based PWM strategy. This decoupling is ensured by introduction of a vector control which will maintain stator current producer of the electromagnetic torque, obtained by imposing by the means of the direct components of stator currents not null. Furthermore, to guarantee this operation with optimal torque working in all regimes as in the case of a DC machine, we have introduced a regulation of a rotor current through a chopper operating at $5 \mathrm{KHz}$ chopping frequency, feeding the excitation rotor circuit.

\section{THE PROPOSED SYSTEM}

Figure 1 illustrates the synoptic scheme of a DSSM control drive. The machine is a salient-pole type with a dual-stator three-phase winding whose the windings are shifted of 30 electrical degrees one compared to the other, supplied by two independent three-level inverters which are controlled by PWM hysteresis strategy. Because of the salient-pole type, a vector control with imposing constant d-axis stator current was proposed in order to decouple the machine model. A classical PI speed regulator was introduced with the closed-loop regulation.

\subsection{Modeling of the double star synchronous machine}

The studied machine is a double star synchronous machine (DSSM) with stator is made up of two three-phase windings shifted between them of an angle $\left(30^{\circ}\right)$, and an exciting winding shifted compared to the axis of the stator phase of an angle measuring the position of the rotor [3]. The machine is a coiled rotor and with poles without damper windings. For the variation speed, we will use the principle of the self-control which consists in supplying the machine with a current whose frequency and phase are controlled to the rotor position.

The modeling of the machine is based on the usual assumptions such as the effect of saturation is neglected, the distribution of induction along the air-gap is sinusoidal and the effect of the damper windings is neglected. On a reference frame related to the rotating field, the system of $d-q$ equations is [3]

$$
\left(\begin{array}{c}
v_{d 1} \\
v_{d 2} \\
v_{q 1} \\
v_{q 2}
\end{array}\right)=R_{s}\left(\begin{array}{c}
i_{d 1} \\
i_{d 2} \\
i_{q 1} \\
i_{q 2}
\end{array}\right)+\left(\begin{array}{cccc}
\frac{\mathrm{d}}{\mathrm{d} t} & 0 & \omega & 0 \\
0 & \frac{\mathrm{d}}{\mathrm{d} t} & 0 & \omega \\
-\omega & 0 & \frac{\mathrm{d}}{\mathrm{d} t} & 0 \\
0 & -\omega & 0 & \frac{\mathrm{d}}{\mathrm{d} t}
\end{array}\right)\left(\begin{array}{c}
\phi_{d 1} \\
\phi_{d 2} \\
\phi_{q 1} \\
\phi_{q 2}
\end{array}\right) .
$$

The rotor excitation circuit is written as

$$
V_{f}=R_{f} i_{f}+\frac{\mathrm{d} \phi_{f}}{\mathrm{~d} t}
$$

and the corresponding flux relations are given by

$$
\begin{aligned}
\phi_{d 1} & =L_{d} i_{d 1}+M_{d} i_{d 2}+M_{f d} i_{f}, \\
\phi_{d 2} & =L_{d} i_{d 2}+M_{d} i_{d 1}+M_{f d} i_{f}, \\
\phi_{q 1} & =L_{q} i_{q 1}+M_{q} i_{q 2}, \\
\phi_{q 2} & =L_{q} i_{q 2}+M_{q} i_{q 1}, \\
\phi_{f} & =L_{f} i_{f}+M_{f d}\left(i_{d 1}+i_{d 2}\right) .
\end{aligned}
$$

The mechanical equation is:

$$
\frac{J}{p} \frac{\mathrm{d} \omega}{\mathrm{d} t}=T_{e m}-\frac{f_{r}}{p} \omega-T_{r}
$$

The electromagnetic torque developed by the machine is

$$
T_{e m}=p\left(\phi_{d 1} i_{q 1}-\phi_{q 1} i_{d 1}+\phi_{d 2} i_{q 2}-\phi_{q 2} i_{d 2}\right) \text {. }
$$

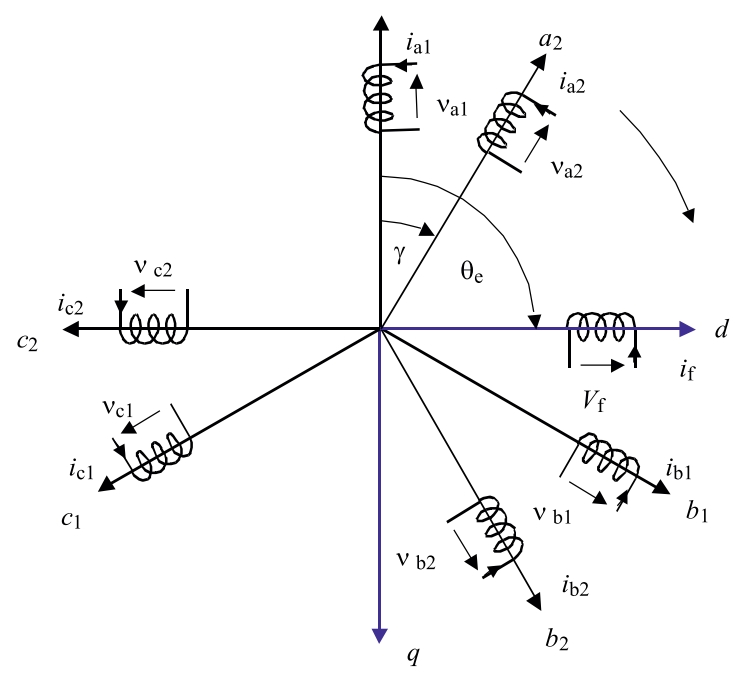

Fig. 2. Schematic representation of the DSSM windings

\subsection{Power supply of the machine}

By their principle, the synchronous machines can operate at variable speed only if they are fed by static inverters at frequency variable and controlled to the rotor position. The converters of power supply of the machine schematized on Fig. 3a are three-level inverters with NPC structure whose each inverter consists of twelve bidirectional switches $\left(K_{i j}\right)$ and each switch is made of a transistor and a recovery diode. Level zero of the output voltage is obtained by two diodes connected to the point-medium of the dc-link voltage supplying the inverters (Fig. 3b). All these elements are assumed to be perfect switches. This structure, intended for applications of high power 

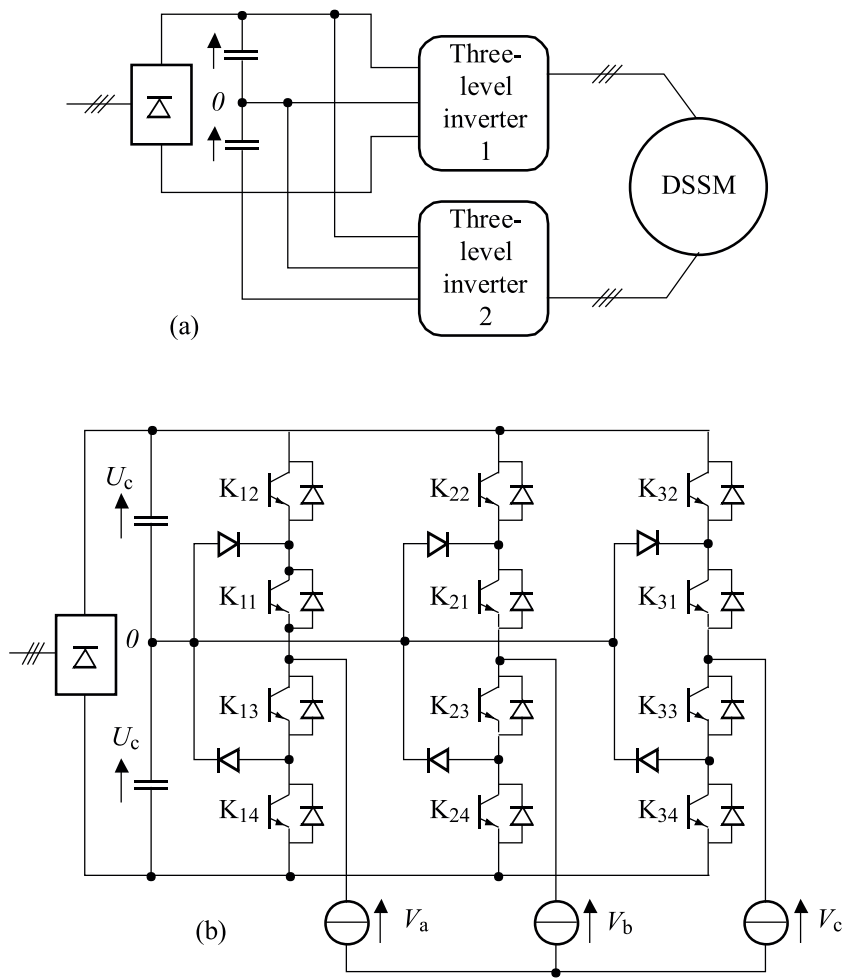

Fig. 3. (a) - Supplying of DSSM scheme by three-level inverters, (b) - Scheme of three-level inverter NPC structure

makes it possible to have a voltage waveform closer to the sinusoid than with the traditional structure of twolevel inverter. Moreover, for the same dc-link voltage, the three-level inverter switches support half of the voltage supported by those of the two-level inverter [6].

For the control PWM strategy of the inverters, the adjustment is carried out by the duration of opening and closing of the switches, and by operation sequence. For our study, we apply the hysteresis-based PWM strategy whose principle consists in maintaining the variation of the current for each phase, in a band framing the current reference, using an appropriate control of the inverter switches. This control is achieved by a permanent comparison between the real stator current and its reference. Thus, the converter will behave as a current fed inverter whose structure is in voltage.

\section{VECTOR CONTROL STRATEGY UNDER OPTIMAL TORQUE OPERATION}

The model of the double star synchronous machine is multivariable, highly coupled and nonlinear. The speed control of this machine and thus torque requires the simultaneous control of several variables. Indeed, the distinction between the current producer of the torque and the one producer of the flux is not as evident as in the case of the DC machine. In order to obtain the desired performances, the control strategy of the AC machines often consists in making the electromechanical behavior similar to that of a DC machine. This similarity is carried out by the application of the vector control $[7,10,11]$.

The main objective is to decouple the electromagnetic torque from the direct components of stator flux and thus to control the torque it is necessary to impose the components of the two stator currents $i_{d 1}, i_{d 2}, i_{q 1}, i_{q 2}$. In the case of a machine with smooth poles, the electromagnetic torque is optimal for a decoupled control strategy with $i_{d 1}=0$ and $i_{d 2}=0$ [10], but for machine that we study who is with salient poles $\left(L_{d}=196.1 \mathrm{mH}\right.$, $L_{q}=110.5 \mathrm{mH}$ ), the developed electromagnetic torque is not optimal for this control strategy but for an other one with $i_{d 1} \neq 0$ and $i_{d 2} \neq 0$ and thus the electromagnetic torque takes a value proportional to $\left(i_{q 1}+i_{q 2}\right)$ for a given rotor excitation. After this choice, one obtains a model where $\left(i_{q 1}, i_{q 2}\right)$ components command only the electromagnetic torque.

On the basis of the relations (3) and (5) and supposing that the two inverters provide equitably half of the consumption by the machine, one writes

$$
\begin{aligned}
& i_{d 1}=i_{d 2}=i_{d}, \\
& i_{q 1}=i_{q 2}=i_{q} .
\end{aligned}
$$

The torque is expressed as

$$
T_{e m}=2 p\left[\left(L_{d}-L_{q}+M_{d}-M_{q}\right) i_{d}+M_{f d} i_{f}\right] i_{q} .
$$

For a fixed excitation rotor current $i_{f}$, the electromagnetic torque is proportional to the $i_{q}$ component of the stator current if however its $i_{d}$ component is maintained constant. Thus, it is possible to impose by the means of the $i_{d}$ component an operating at optimal torque and stator flux constant. Indeed for the imposed following nominal values $\phi_{s n}=1.52 \mathrm{~Wb}$ and maximum value of stator current $i_{s \max }=\sqrt{2} i_{\text {snom }}=7.6 \mathrm{~A}$, we write

$$
\begin{aligned}
\phi_{s n}^{2} & =\phi_{d}^{2}+\phi_{q}^{2} \\
\phi_{d} & =\left(L_{d}+M_{d}\right) i_{d}+M_{f d} i_{f} \\
\phi_{q} & =\left(L_{q}+M_{q}\right) i_{q} .
\end{aligned}
$$

By holding account owing to the fact that $i_{q}^{2}=i_{s \max }^{2}-i_{d}^{2}$, the quadratic equation of $i_{d}$ component is given by

$$
\begin{array}{r}
{\left[\left(L_{d}+M_{d}\right)^{2}-\left(L_{q}+M_{q}\right)^{2}\right] i_{d}^{2}+2\left(L_{d}+M_{d}\right) M_{f d} i_{f} i_{d}} \\
+\left(L_{q}+M_{q}\right)^{2} i_{s \max }^{2}-\phi_{s n}^{2}+M_{f d}^{2} i_{f}^{2}=0
\end{array}
$$

and while posing

$$
\begin{aligned}
i_{\xi} & =\frac{\left(L_{d}+M_{d}\right) M_{f d} i_{f}}{\left(L_{d}+M_{d}\right)^{2}-\left(L_{q}+M_{q}\right)^{2}} \\
i_{\omega}^{2} & =\frac{\left(L_{q}+M_{q}\right)^{2} i_{s \max }^{2}-\phi_{s n}^{2}+M_{f d}^{2} i_{f}^{2}}{\left(L_{d}+M_{d}\right)^{2}-\left(L_{q}+M_{q}\right)^{2}} .
\end{aligned}
$$

The solution of this quadratic equation is

$$
i_{d}=-i_{\xi} \pm \sqrt{i_{\xi}^{2}-i_{\omega}^{2}} .
$$




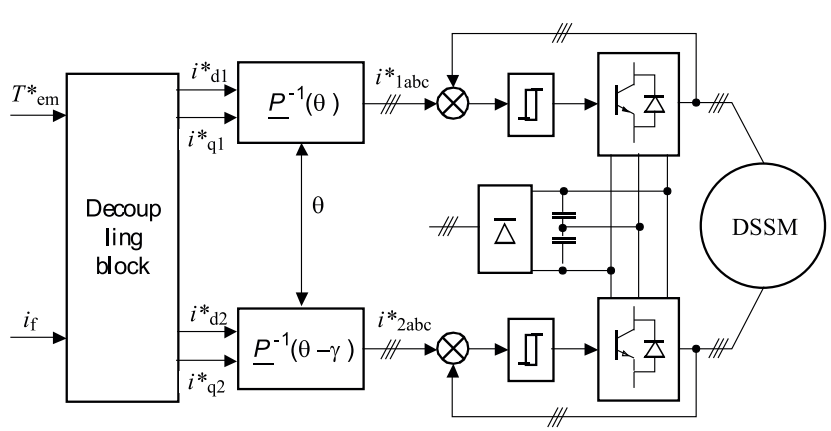

Fig. 4. Decoupled control scheme of a DSSM feeding by three-level inverters

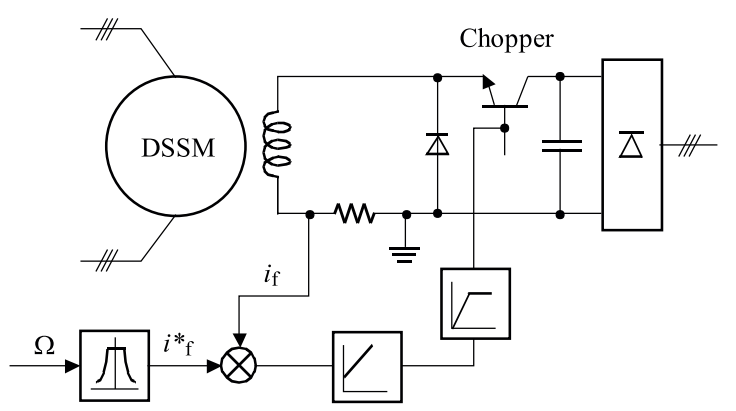

Fig. 5. Regulation of rotor current with a chopper feeding

The one of numerical values of $i_{d}$ component is $-3 \mathrm{~A}$ and the other value is rejected, for the imposed nominal values $\left(\phi_{s n}=1.52 \mathrm{~Wb}, i_{s \max }=7.6 \mathrm{~A}\right.$ and $\left.i_{f}=1 \mathrm{~A}\right)$.

Figure 4 illustrates the scheme of vector control-DSSM supplied by two three-level inverters, the decoupled control strategy of the machine is ensured by the decouplingblock obtained by the model of the machine. Indeed, for an optimal operating of the torque, we impose the $d$ axis $\left(i_{d 1}, i_{d 2}\right)$ components on their constant values given by the relation (11) and we establish the $q$-axis $\left(i_{q 1}, i_{q 2}\right)$ components by the means of the reference torque $T_{e m}^{*}$, the decoupling structure can written as

$$
\begin{aligned}
& i_{d 1}^{*}=i_{d 1}^{*}=i_{d}^{*}=-i_{\xi}+\sqrt{i_{\xi}^{2}-i_{\omega}^{2}} \\
& i_{q 1}^{*}=i_{q 2}^{*}=\frac{T_{e m}^{*}}{2 p\left[L_{d}+M_{d}-L_{q}-M_{q}\right] i_{d}^{*}+M_{f d} i_{f}} .
\end{aligned}
$$

The reference components of stator currents $\left(i_{d 1}^{*}, i_{d 2}^{*}\right.$, $\left.i_{q 1}^{*}, i_{q 2}^{*}\right)$ which are provided by this block ensure the control of the torque and the passage to the real variables is done by use the inverse generalized Park transform, then

$$
\begin{aligned}
\left(\begin{array}{l}
i_{a 1}^{*} \\
i_{b 1}^{*} \\
i_{c 1}^{*}
\end{array}\right) & =P^{-1}(\theta)\left(\begin{array}{c}
i_{d 1}^{*} \\
i_{q 1}^{*}
\end{array}\right)= \\
& \sqrt{\frac{2}{3}}\left(\begin{array}{cc}
\cos \theta & -\sin \theta \\
\cos \left(\theta-\frac{2 \pi}{3}\right) & -\sin \left(\theta-\frac{2 \pi}{3}\right) \\
\cos \left(\theta+\frac{2 \pi}{3}\right) & -\sin \left(\theta+\frac{2 \pi}{3}\right)
\end{array}\right)\left(\begin{array}{l}
i_{d 1}^{*} \\
i_{q 1}^{*}
\end{array}\right)
\end{aligned}
$$

and

$$
\begin{aligned}
& \left(\begin{array}{l}
i_{a 2}^{*} \\
i_{b 2}^{*} \\
i_{c 2}^{*}
\end{array}\right)=P^{-1}(\theta-\gamma)\left(\begin{array}{c}
i_{d 2}^{*} \\
i_{q 2}^{*}
\end{array}\right)= \\
& \sqrt{\frac{2}{3}}\left(\begin{array}{cc}
\cos (\theta-\gamma) & -\sin (\theta-\gamma) \\
\cos \left(\theta-\gamma-\frac{2 \pi}{3}\right) & -\sin \left(\theta-\gamma-\frac{2 \pi}{3}\right) \\
\cos \left(\theta-\gamma+\frac{2 \pi}{3}\right) & -\sin \left(\theta-\gamma+\frac{2 \pi}{3}\right)
\end{array}\right)\left(\begin{array}{c}
i_{d 2}^{*} \\
i_{q 2}^{*}
\end{array}\right) .
\end{aligned}
$$

Where $\theta=\int \omega \mathrm{d} t$ and $\gamma=\pi / 6$.

\section{EXCITATION ROTOR CURRENT REGULATION}

For a given load, the electromagnetic torque depends on the rotor excitation current. In order to ensure the decoupling of the machine with optimal torque in all regimes, in particular at starting, it is necessary to control this current. To this end, we introduce a transistor chopper operating at $5 \mathrm{KHz}$ chopping frequency, feeding the excitation DC circuit. The control of the rotor current is ensured by a PI regulator and the reference excitation current is given by a defluxing-block which allows the working of the machine beyond the nominal speed (Fig. 5).

Using the control strategy given by equation (11), the rotor equation is rewritten as

$$
V_{f}=R_{f} i_{f}+L_{f} \frac{\mathrm{d} i_{f}}{\mathrm{~d} t} .
$$

The PI controller parameters $K_{p}$ and $K_{i}$ are determined by pole placement method developed for the linear systems [12]. The closed-loop is given in fig. 6 . The closedloop transfer function is given by

$$
\frac{i_{f}(s)}{i_{f}^{*}(s)}=\frac{1}{L_{f}} \frac{s K_{p}+K_{i}}{s^{2}+\frac{R_{f}+K_{p}}{L_{f}} s+\frac{K_{i}}{L_{f}}} .
$$

To get a well damped behaviour, we use the poles placement approach proposed by [12], schematized in fig. 7 .

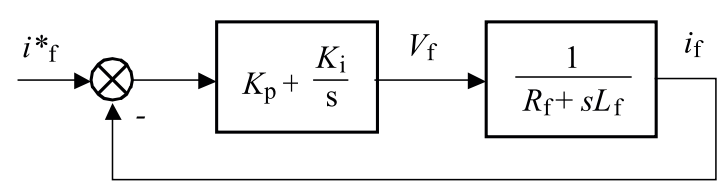

Fig. 6. Closed loop excitation rotor current

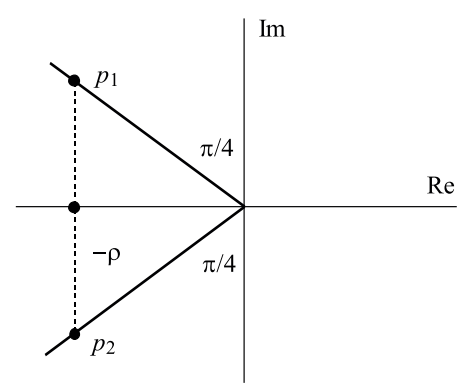

Fig. 7. Poles placement method 


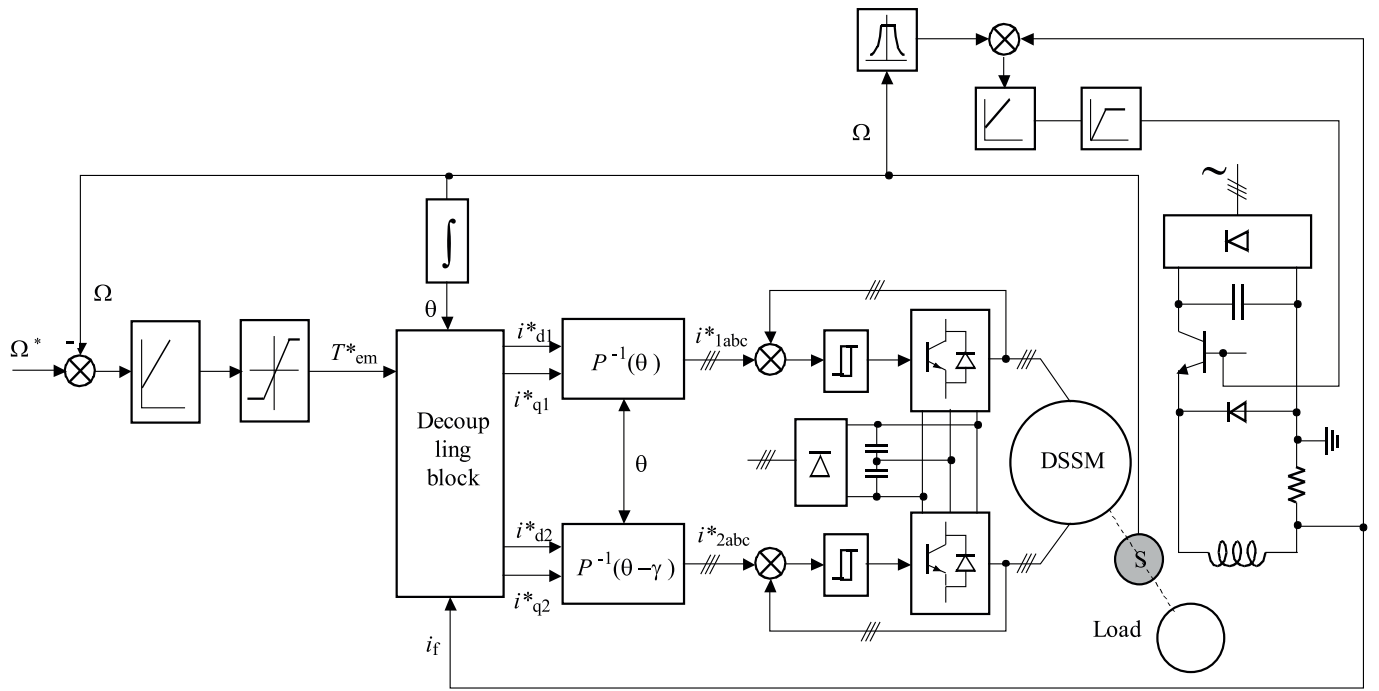

Fig. 8. Schematic diagram of vector control DSSM in closed-loop speed regulation and excitation rotor current regulation
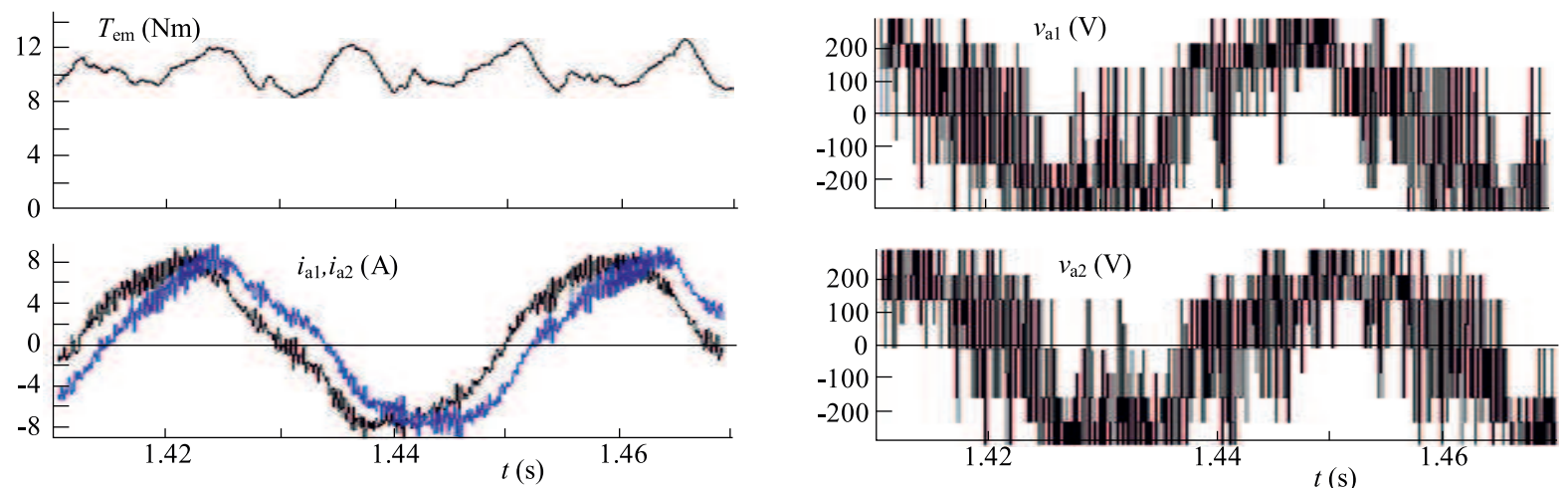

Fig. 9. Instantaneous waveforms in study-state behaviour of torque, voltages and stator currents in the case of a hysteresis PWM strategy with $\delta=0.5 \mathrm{~A}$ and load torque of $16 \mathrm{Nm}$
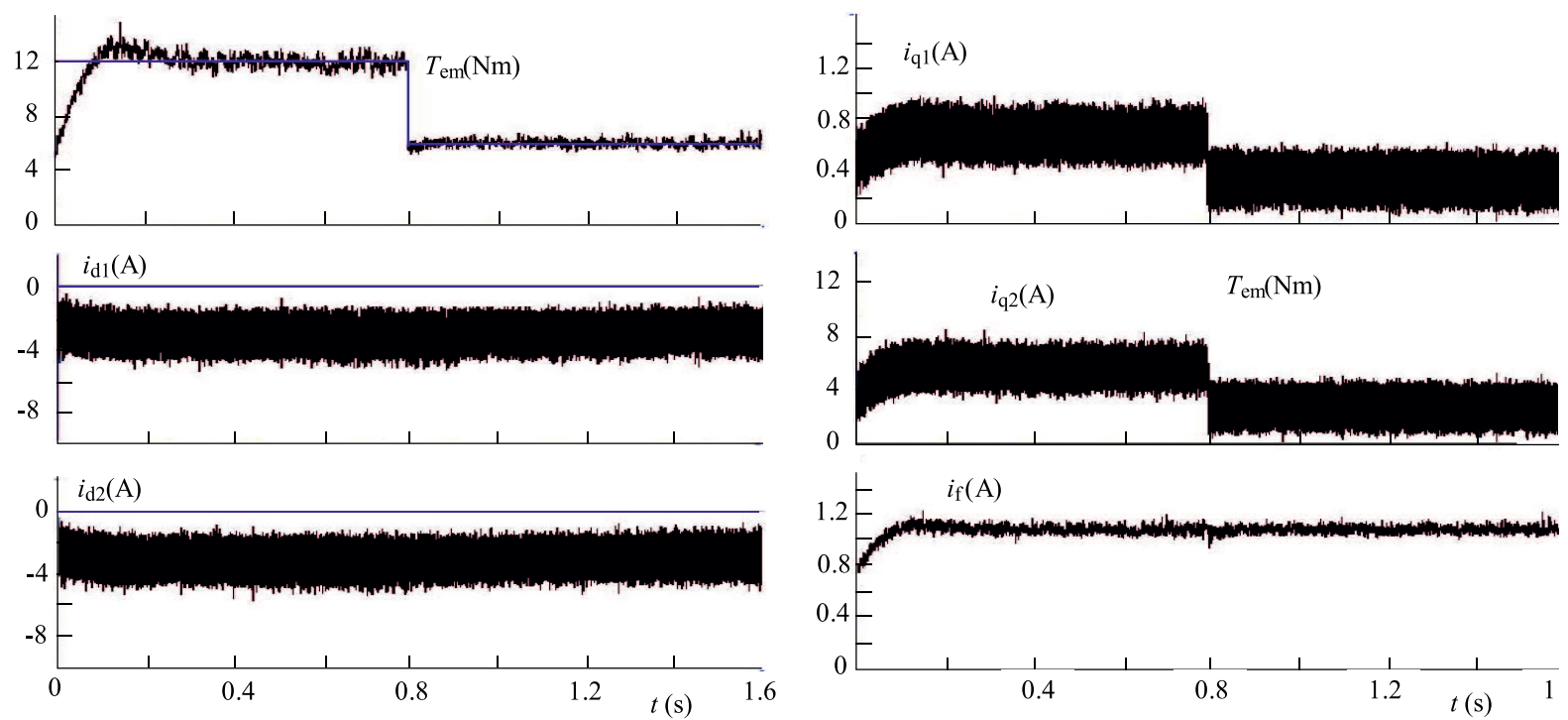

Fig. 10. Performances of the vector control of the DSSM in open loop with the excitation rotor DC current regulation with reference value $i_{f}^{*}=1 \mathrm{~A}$ and $\rho=1.1$. Waveforms of torque, amplitudes of $d-q$ stator current components and DC rotor current

Let $p_{1}=-\rho-j \rho$ and $p_{2}=-\rho+j \rho$, by identification, The parameters values of PI corrector based on $\rho$ are we obtain

$$
\left(s-p_{1}\right)\left(s-p_{2}\right)=s^{2}+\frac{R_{f}+K_{p}}{L_{f}} s+\frac{K_{i}}{L_{f}} .
$$

$$
\begin{aligned}
K_{p} & =2 \rho L_{f}-R_{f}, \\
K_{i} & =2 \rho^{2} L_{f} .
\end{aligned}
$$



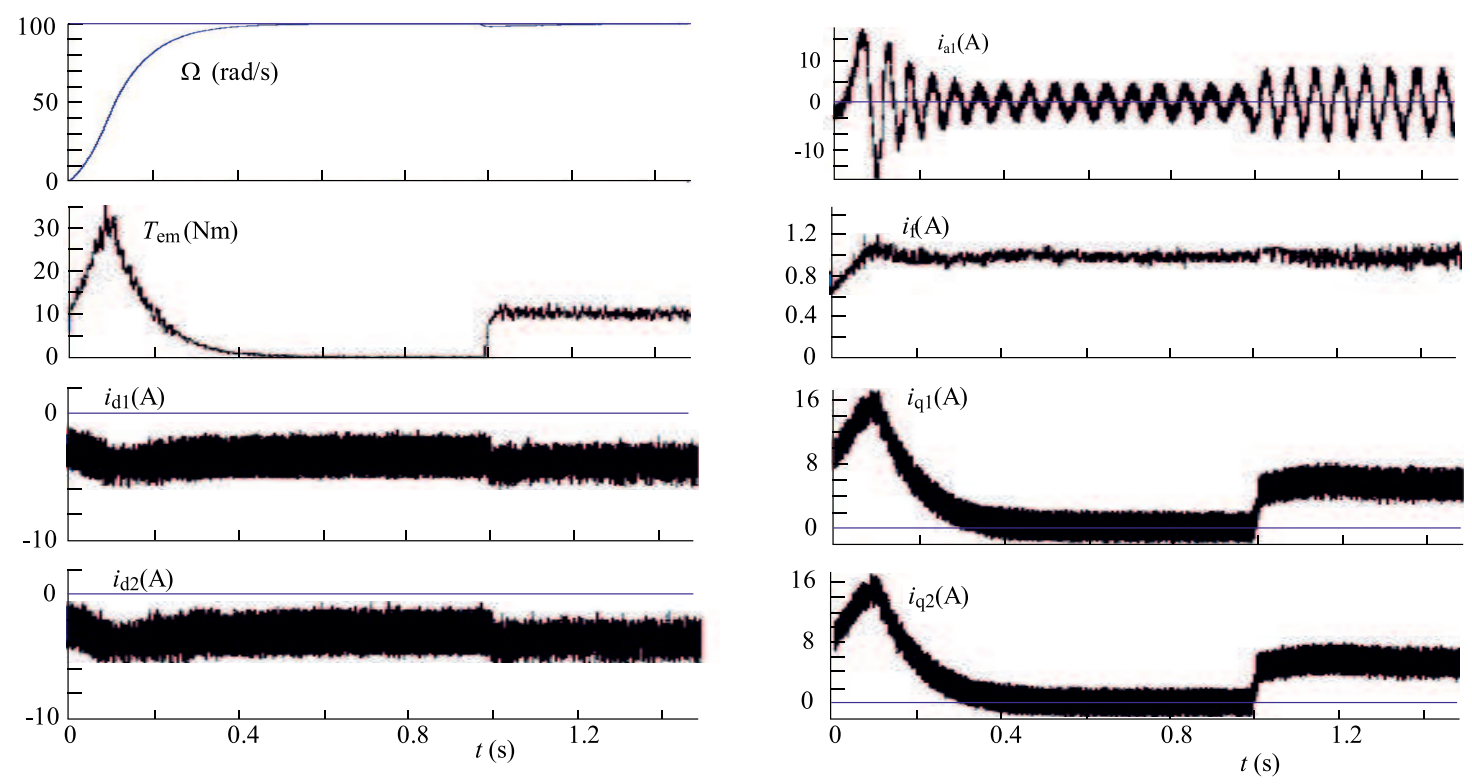

Fig. 11. Performances of the closed loop vector control corresponding to speed step response of $100 \mathrm{rd} / \mathrm{sec}$ with application load torque $T_{r}=10 \mathrm{Nm}$ at time $t=1 \mathrm{sec}$. Waveforms of speed, torque, stator current in phase $a_{1}$, DC rotor current and amplitudes of $d-q$ stator current components $(\rho=10)$
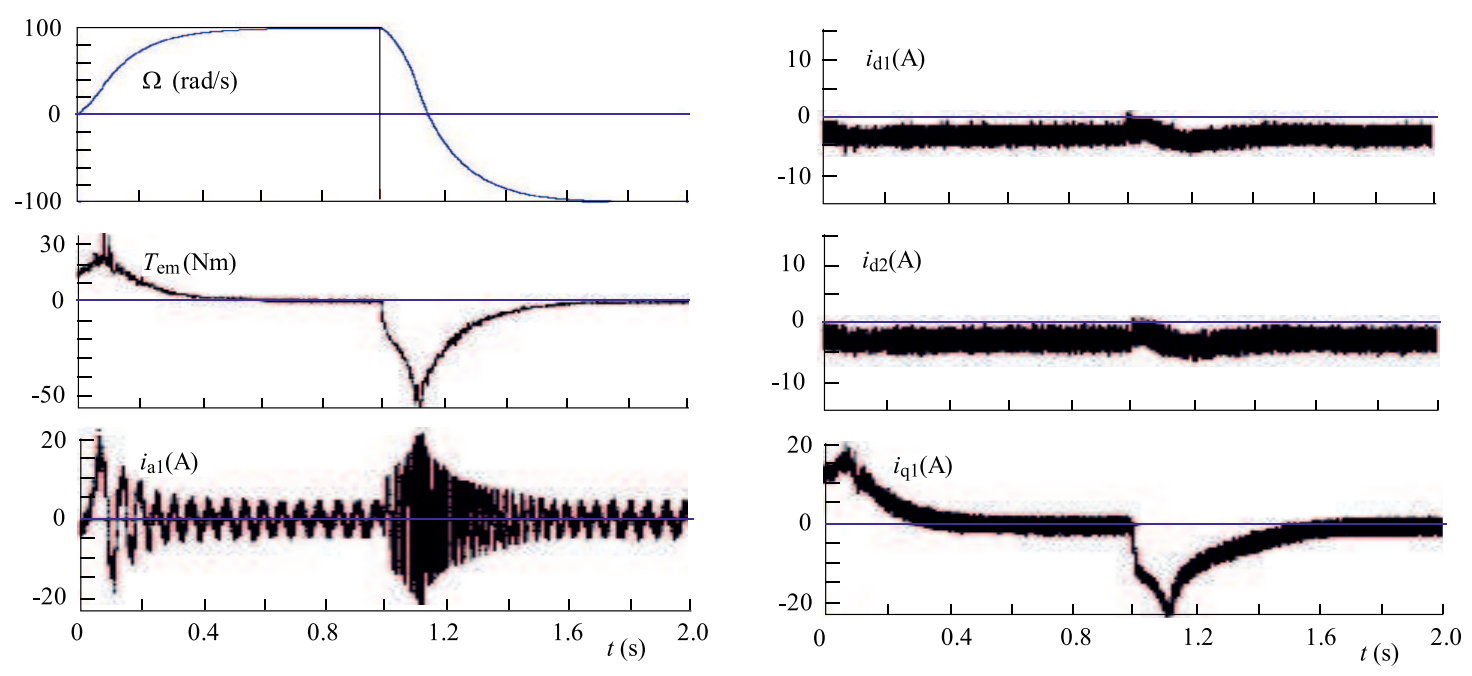

Fig. 12. Performances of the closed-loop vector control corresponding to a speed square step response $100 \mathrm{rd} / \mathrm{s},-100 \mathrm{rd} / \mathrm{s}$. Waveforms of speed, torque, stator current in phase $a_{1}$, amplitudes of $d-q$ stator current components $(\rho=10)$

\section{SIMULATION AND RESULTS}

To evaluate the performances of the vector control of the DSSM in closed loop regulation with PI speed corrector and rotor current regulation, we simulate the global working of the system given in Fig. 8.

The nominal power of the DSSM machine is $5 \mathrm{~kW}$ and the nominal torque is $16 \mathrm{Nm}$. This machine is supplied by two independent three-level inverters which are controlled by PWM hysteresis strategy whose hysteresis band is $0.5 \mathrm{~A}$ ie $10 \%$ of the rated stator current approximately.

Figure 9 illustrates the instantaneous waveforms of stator current waves, the supply voltages and the electromagnetic torque developed by the machine in steady- state regime. One can see the clear sinusoidal shape of the currents and the weak undulations of the torque.

Figure 10 shows the performances of the vector control in open loop (without regulation speed) with rotor current regulation which we introduced in order to ensure a behaviour model similar to that of a DC machine. Indeed, we imposed a reference torque of $12 \mathrm{Nm}$ in the time interval of $[0,0.8] \mathrm{sec}$ and of $6 \mathrm{Nm}$ in the time interval of $[0.8,1.6] \mathrm{sec}$ and we note that the developed torque follows perfectly the posted reference and that it is the image of the stator current components $i_{q 1}$ and $i_{q 2}$. Moreover the components $i_{d 1}$ and $i_{d 2}$ are appreciably equal to the decoupling reference components which is of $(-3 \mathrm{~A})$ even to starting, which shows the decoupling effect. 
In Figs.11 and 12 we have shown the obtained performances for the closed loop vector control of the DSSM drive. One can see the waveforms of the speed, the torque, the amplitudes of stator current components $\left(i_{d 1}, i_{d 2}, i_{q 1}, i_{q 2}\right)$ and the excitation rotor current $i_{f}$. A torque limiter was also introduced in order to limit the produced torque to its acceptable value of $40 \mathrm{Nm}$. The tests were carried out as follows

- Fig. 11: speed step response of $100 \mathrm{rd} / \mathrm{s}$ with load torque $T_{r}=10 \mathrm{Nm}$ application at time $t=1 \mathrm{sec}$.

- Fig. 12: speed square step response $100 \mathrm{rd} / \mathrm{s},-100 \mathrm{rd} / \mathrm{s}$ while the machine is not loaded.

For the two tests, we notice that speed follows perfectly its imposed reference without going beyond and the disturbance rejection is immediate. The amplitude value of $d$-axis current components $i_{d 1}$ and $i_{d 2}$ are always maintained with the optimal reference value of $(-3 \mathrm{~A})$ and keep this value in spite of the severe disturbances imposed on the system. One also confirms that the electromagnetic torque and the amplitude value of $q$-axis current components $i_{q 1}$ and $i_{q 2}$ have rigorously the same form.

\section{CONCLUSION}

The application of the vector control to the salient-pole DSSM permitted to simplify the model of the machine and to decouple it. By this process, the performances of the machine supplied by two three-level inverters controlled via the hysteresis PWM strategy, are interesting to know an appreciable dynamic behavior and a rejection of effective disturbance. The obtained results are very satisfactory and reveal the effectiveness of the proposed approach.

For the salient-pole DSSM type, the developed torque is optimal for a decoupling model with $i_{d 1} \neq 0$ and $i_{d 2} \neq$ 0 values and thus the torque takes a value proportional to $\left(i_{q 1}+i_{q 2}\right)$ for a given excitation. After this choice, one obtains a model where the $i_{q 1}$ and $i_{q 2}$ components only command the electromagnetic torque.

Also, in order to ensure the decoupled behavior from the machine with constant torque, as in the case of a DC machine, we introduced an excitation current regulating on its reference gotten by a defluxing-block which allows the working of the machine beyond the nominal speed. This operation is obtained through a chopper feeding the excitation rotor circuit with chopping frequency of $5 \mathrm{KHz}$

As perspectives, we can replace the speed PI regulator by a robust regulator gotten by the advanced automatic techniques as the control by sliding mode or the fuzzy logic.

\section{REFERENCES}

[1] LODDICK, S. J. : The Design and Application of a 7 MW Synchronous Machine Variable Speed Drive, IEE, Power Electronics and Variable Speed Drives. 21-23 September 1998, Conference publication No. 456, pp. 224-229.

[2] TERRIEN, F.-BENKHORIS, M. F. : Analysis of Double-Star Motor for Electrical Propulsion, IEE, $9^{\text {th }}$ International Conference on Electrical Machines and Drives (EMD99), UK, 1-3 September 1999, pp. 90-95.

[3] TERRIEN, F.-BENKHORIS, M. F. : Modelling and Study of Double Star Alternative Machine Power Electronic Converter-Set, Proceeding of Electrimacs99, Lisbon, Portugal, 14-16 September 1999, pp. 195-200.

[4] KHeloui, A.-MEIBODY-TABAR, F.-DAvAT, B. : Current Commutation Analysis in Self-Controlled Double-Stator Synchronous Machines Taking into Account Saturation Effect, Electric Machines and Power Systems (EMPS95), No. 23, 1995, pp. 557-569.

[5] JONES, M.-VUKOSAVIC, S. N.-LEVI, E.-IQBAL, A. : A Six-Phase Series-Connected Two-Motor Drive with Decoupled Dynamic Control, IEEE Trans. on Industrial Application 41 No. 4 (July/Aug 2005), 1056-1065.

[6] BERIBER, D.-BERKOUK, E. M.-MAHMOUDI, MO.TALHA, A.: Study and Control of Two Level PWM Rectifiers-Clamping Bridge Two Three Level NPC VSI Cascade. Application to Double Stator Induction Motors, PESC/CIPS 2004 Conference, June 20-25, 2004, Germany.

[7] VAS, P.: Vector Control of AC Machines, Oxford Science Publication, 1994.

[8] SEN, P. C. : Electric Motor Drives and Control - Past, Present and Future, IEEE Trans. on Industrial Electronics 37 No. 6 (1999), 526-575.

[9] BENKHORIS, M. F.-TALI-MAAMAR, N.-TERRIEN, F.: Decoupling Algorithm in View of Multivariable Electrical Drives Control, Proceedings of the American Control Conference, Anchorage, AK May 8-10, 2002, pp. 4861-4866.

10] NEZLI, L.-MAHMOUDI, M. O.-BOUCHERIT, M. S.DJEMAI, M.: On Vector Control of Double Star Synchronous Machine with Current Fed Inverters, The Mediterranean Journal of Measurement and Control 1 No. 3 (July 2005), 118-128.

[11] LEVI, E.-VUKOSAVIC, S. N.-JONES, M. : Vector Control Schemes for Series-Connected Six-Phase Two-Motor Drive Systems, IEE Proceedings Electrical Power Application 152 No. 2 (March 2005), 226-238.

12] BÜHLER, H. : Conception des systèmes automatiques, Presses Polytechniques Rommandes, Lausane, 1988.

Received 15 December 2009

Lazhari Nezli, was born in 1957. He received the electrical engineering degree, the Magister degree and the doctorate degree from the national polytechnic school of Algiers (Algeria) in 1982, 1986 and 2006 respectively. Since1987, he holds teaching and research positions at the department of electrical engineering ENP, where he is currently assistant professor. His research interest are in Modeling and electrical machines drives.

Mohand Oulhadj Mahmoudi was born in Algiers (Algeria) in 1956. He received the Engineer diploma, the Magister degree and the doctorate degree in Electrical Engineering from the national polytechnic school of Algiers (Algeria) in 1982, 1986 and 1999 respectively. Since 1986, he holds teaching and research positions at the electrical engineering department (ENP) where he is currently full professor. His areas of research interest are in Power Electronics and Electric Machines and Drives. 